\title{
B-type natriuretic peptide levels predict outcomes for children on extracorporeal life support after cardiac surgery
}

Omar Chikovani, MD, ${ }^{\mathrm{a}, *}$ Jong-Hau Hsu, MD, ${ }^{\mathrm{a}, \mathrm{e}, *}$ Roberta Keller, MD, ${ }^{\mathrm{a}}$ Tom R. Karl, MD, ${ }^{\mathrm{b}, \mathrm{c}}$ Anthony Azakie, MD, ${ }^{\mathrm{b}, \mathrm{c}}$ Ian Adatia, MBChB, ${ }^{a, c}$ Peter Oishi, MD, and Jeffrey R. Fineman, MD ${ }^{a, c, d}$

From the Departments of Pediatrics ${ }^{\mathrm{a}}$ and Surgery, ${ }^{\mathrm{b}}$ the Pediatric Heart Center, ${ }^{\mathrm{c}}$ and the Cardiovascular Research Institute, ${ }^{\mathrm{d}}$ University of California, San Francisco, Calif; and the Department of Pediatrics, Kaohsiung Medical University Hospital, Taiwan.

This research was supported in part by grants K08 HL086513 (to P.O.), K23 HL079922 (to R.L.K.), and HL61284 and MO1RR01271 (to J.R.F.), from the National Institutes of Health, Fondation Leducq (to J.R.F.), and from Biosite Diagnostic. J.H.H. was supported in part by the Department of Pediatrics, Kaohsiung Medical University Hospital, Taiwan. J.R.F. reports grant support from Biosite, Inc.

Received for publication Dec 15, 2006; revisions received March 13, 2007; accepted for publication April 9, 2007.

Address for reprints: Jeffrey R. Fineman, MD, Department of Pediatrics, University of California, San Francisco, 505 Parnassus Ave, Box 0106, San Francisco, CA 941430106 (E-mail: jeff.fineman @ucsf.edu).

*These authors contributed equally.

J Thorac Cardiovasc Surg 2007;134:1179-87 $0022-5223 / \$ 32.00$

Copyright (C) 2007 by The American Association for Thoracic Surgery

doi:10.1016/j.jtcvs.2007.04.023
Objective: Extracorporeal life support is used in 3\% to $8 \%$ of infants and children after cardiac surgery. B-type natriuretic peptide may have utility as a biomarker in these patients. The objective of this study was to investigate potential associations between changes in B-type natriuretic peptide during trials off extracorporeal life support and clinical outcome.

Methods: Ten infants and children requiring extracorporeal life support after cardiac surgery were studied prospectively. Before separation from extracorporeal life support, a shunt was placed in the circuit, allowing for temporary trials off life support. Serum lactate, arterial-venous oxyhemoglobin saturation difference, and B-type natriuretic peptide levels were determined before each trial off life support and at the end of each trial off life support, and the ability to predict postoperative outcome from these data was evaluated.

Results: During trials off extracorporeal life support, lactate, the arterial-venous oxyhemoglobin saturation difference, and B-type natriuretic peptide levels increased above pre-trial values $(P<.05)$. Only the arterial-venous oxyhemoglobin saturation difference predicted successful separation from extracorporeal life support after a trial $(P<.05)$. There were no associations between long-term outcome and alterations in lactate and the arterial-venous oxyhemoglobin saturation difference during the final trials off life support. However, an increase in B-type natruiretic peptide levels during the final trial off life support (trial/pre-trial ratio of $>1$ ) had a sensitivity of $80 \%$ and a specificity of $100 \%$ for predicting the need for an unplanned operation or death within 3 months $(P<.05)$.

Conclusion: B-type natriuretic peptide determinations may be a useful tool for clinicians caring for infants and children requiring extracorporeal life support after cardiac surgery.

$\mathrm{E}$ xtracorporeal life support (ECLS) is used in $3 \%$ to $8 \%$ of infants and children after corrective or palliative surgery for congenital cardiac defects. ${ }^{1-5} \mathrm{Al}-$ though historically a rescue therapy, technologic advances and accumulated clinical experience have expanded the indications for ECLS to permit earlier initiation and even prophylactic treatment of low cardiac output syndrome. ${ }^{6-9}$ Consequently, patients supported with ECLS are an increasingly heterogeneous group, with some who require only time for recovery and others who require further interventions. Distinguishing between these types of patients is important to minimize the duration of ECLS and to ensure that patients requiring further investigations and interventions are identified. Thus, much of the clinical focus during ECLS is aimed at assessing recovery of cardiovascular function. One common method involves trials off ECLS that are achieved by placing a shunt in the ECLS circuit, allowing mechanical support to be temporarily stopped, but keeping the cannulas 


\author{
Abbreviations and Acronyms \\ $\mathrm{AVdO}_{2}=$ arterial-venous oxyhemoglobin saturation \\ difference \\ $\mathrm{BNP}=\mathrm{B}$-type natriuretic peptide \\ $\mathrm{CPB}=$ cardiopulmonary bypass \\ ECLS = extracorporeal life support \\ PCICU $=$ pediatric cardiac intensive care unit
}

and circuit components free of thrombosis and ready for immediate resumption. During these trials off ECLS, cardiovascular function is assessed by observing the hemodynamic response and through the measurement of various markers of cardiac output, such as lactate, central venous hemoglobin saturation, acid-base status, and urine output. ${ }^{3}$ Unfortunately, none of these factors has been shown to adequately predict either a readiness to separate from ECLS or the need for further intervention. ${ }^{1}$ Thus, novel biomarkers that might aid in these assessments are needed.

B-type natriuretic peptide (BNP) is a 32-amino acid polypeptide hormone with diuretic, natriuretic, and vasoactive properties. As a cardiac hormone produced by the atria and ventricles in response to myocyte stretch, it has been shown to have unique clinical utility as a biomarker and is thus widely used in the management of adult cardiac disease, with an emerging use in pediatric cardiac disease. ${ }^{10-15}$ In fact, BNP has been studied in adult and pediatric patients requiring mechanical cardiac support. ${ }^{16-20}$ However, the value of BNP levels in predicting successful separation from ECLS or in predicting outcome after surgery, including the need for further interventions, has not been established.

Thus, the objectives of this study were (1) to determine whether alterations in BNP during trials off ECLS were associated with our ability to separate patients from ECLS and (2) to investigate potential associations between changes in BNP during trials off ECLS and outcome. We prospectively studied 9 infants and children who required ECLS after cardiac surgery. Systemic arterial plasma BNP determinations were made before and during each trial off ECLS, and whether a change in BNP could predict separation from ECLS, and/or postoperative outcome was evaluated.

\section{Materials and Methods}

This prospective cohort study was conducted in the Pediatric Cardiac Intensive Care Unit (PCICU) at the University of California, San Francisco, between March 2005 and June 2006. Patients with congenital cardiac defects undergoing surgical repair were enrolled and patients requiring postoperative ECLS were included in the study.

The patients were followed up during their entire course in the PCICU. The perioperative anesthesia management, cardiopulmo- nary bypass (CPB) strategy, and subsequent PCICU management followed standard institutional practices. An on-service team that was blinded to the BNP values made all decisions regarding patient management.

Written informed consent was obtained from the patients' parents or guardians before enrollment of the patients into the study. The Institutional Review Board at the University of California, San Francisco, reviewed and approved this study.

\section{Indications for ECLS}

The indications for ECLS included (1) the inability to separate a patient from $\mathrm{CPB}$, necessitating the initiation of ECLS in the operating room, (2) the elective initiation of ECLS in the operating room for low cardiac output after discontinuing $\mathrm{CPB},(3)$ the development of refractory low cardiac output syndrome in PCICU, or (4) postoperative cardiac arrest, with ECLS used as a part of cardiopulmonary resuscitation. Signs of low cardiac output in the operating room or intensive care unit that resulted in the initiation of ECLS included sustained systemic hypotension and/or persistent metabolic acidosis refractory to medical management.

\section{ECLS}

Our techniques for circulatory support have been described in detail previously. ${ }^{21}$ The ECLS circuit was a Medtronic BioMedicus Portable Cardiopulmonary Bypass System 1000, consisting of a centrifugal pump Bio-Console model 550 (BP-50 Bio-Pump; Medtronic Inc, Anaheim, Calif) and a hollow-fiber membrane oxygenator (Mini-max Plus or Affinity NT, Medtronic), in which the whole surface was heparin-bonded. Arterial (left atrial or aortic) and venous (right or common atrial) cannulas were placed through either a transcervical or transsternal approach. Left ventricular decompression with an additional left atrial cannula was used selectively for patients with biventricular hearts and severe left ventricular dysfunction. Systemic-pulmonary shunts were kept open during ECLS. For patients with adequate pulmonary function and oxygenation requiring only left ventricular support without an oxygenator, a single venous cannula was placed in the left atrium and the arterial cannula was placed in the ascending aorta. Circuit flow was targeted at 80 to $120 \mathrm{~mL} \cdot \mathrm{kg}^{-1} \cdot \mathrm{min}^{-1}$ or $150 \mathrm{~mL} \cdot \mathrm{kg}^{-1}$. $\min ^{-1}$ for shunt-dependent patients. Inotropes were discontinued or decreased during ECLS support. Heparin infusions were used in most cases to maintain an activated clotting time of 180 to 220 seconds.

\section{Separation from ECLS}

The decision to discontinue ECLS was based on patients recovering adequate cardiovascular function. To assess native cardiovascular function, we placed a shunt or bridge between the arterial and venous cannulas. With the use of 3-way connectors, ECLS flow was diverted away from the patient, but full flow was maintained across the remainder of the circuit, allowing for trials off ECLS without removal of the cannulas. The cannulas were flushed during this time with a continuous infusion of heparin solution. During trials off ECLS, an observer blinded to the BNP data collected hemodynamic and biochemical data. In most trials, echocardiography was performed to assess ventricular function. ECLS was discontinued, with removal of the cannulas, if the cardiac team believed that cardiovascular function was adequate. These assessments were variably based on the hemodynamic, echocardio- 
graphic, and biochemical data obtained during the trials off ECLS, and the decisions were individualized for each patient. In general, a period of stable hemodynamics with the support of fluid volume loading and inotropic agents, the appearance of improvement in cardiac function by echocardiography as compared with the period before ECLS initiation, and minimal changes in venous oxygen saturation and acid-base status were sought. All members of the cardiac team making these decisions were blinded to the BNP data.

\section{Outcomes}

A good short-term outcome was defined as separation from ECLS after a trial off ECLS. Poor short-term outcome was defined as the need for resumption of ECLS after a trial off ECLS. Good longterm outcome was defined as the absence of death or unplanned operation within 3 months of separation from ECLS. Poor longterm outcome was defined as an unplanned operation within 3 months or death within 3 months of separation from ECLS. BNP levels, hemodynamic data, and other biochemical values were evaluated for their association with these end points.

\section{Data Collection}

Blood samples were obtained from an arterial catheter preoperatively, before each trial off ECLS, and at the end of each trial off ECLS. The samples were immediately placed on ice in chilled ethylenediamine tetraacetic acid tubes and centrifuged at $3000 \mathrm{rpm}$ for 15 minutes at $4^{\circ} \mathrm{C}$. Separated plasma was stored at $-20^{\circ} \mathrm{C}$. Within 7 days of obtaining the sample, the plasma was thawed to room temperature, and BNP levels were measured with a commercially available fluorescence immunoassay (Triage Meter Plus; Biosite Diagnostics, San Diego, Calif). The measurable range of BNP on this device is between 5 and $5000 \mathrm{pg} / \mathrm{mL}$. The estimated coefficient of variation for the assay is $9.2 \%$ to $11.4 \%$.

Clinical and biochemical data were prospectively collected at each sampling point and once daily thereafter by an observer blinded to the BNP data. The clinical data collected included demographics, CPB time, myocardial ischemic time during the operation, duration of ECLS, duration of each weaning trial, duration of mechanical ventilation, inotrope dose, mean systemic arterial pressure, central venous pressure, urine output, and fluid balance. Biochemical data included arterial and venous blood gases, base deficit, and serum lactate levels. The duration of mechanical ventilation was quantified as the number of ventilatorfree days within the first 28 days after the operation, so as to avoid confounding the data with patients who died while receiving mechanical ventilation.

\section{Calculations}

Inotrope use was quantified by a score adapted from Wernovsky and associates. ${ }^{22}$ The score was calculated from the level of inotropic support the patients were receiving (in micrograms per kilogram per minute) at each sampling point according to the following equation: dopamine + dobutamine + ([epinephrine + norepinephrine $\times 100)+($ milrinone $\times 20)$. The arterial-venous oxyhemoglobin saturation difference $\left(\mathrm{AVdo}_{2}\right)$ was calculated as the co-oximetric arterial oxyhemoglobin saturation minus the central venous oxyhemoglobin saturation.

\section{Analysis of the Data}

Data are described as mean \pm standard deviation, range, or percentage, as appropriate. Differences in the continuous variables between good outcome and poor outcome subgroups were tested with the Student $t$ test or Mann-Whitney $U$ test. Differences of variables between subgroups within category were tested with the Fisher exact test. Contingency tables were formulated to determine the sensitivity value, specificity value, positive predictive value, and negative predictive value of changes in serum BNP, lactate, and the $\mathrm{AVdO}_{2}$. Differences of variables within groups at two different time points were compared by paired $t$ test. Correlations between variables were performed by the Spearman rank correlation method. Statistical analyses were performed with the use of Prism (GraphPad Software, Inc, San Diego, Calif).

\section{Results \\ Patients}

A total of 11 patients required ECLS after cardiac surgery and were enrolled in the study. Two patients died without undergoing a trial off ECLS and thus were excluded from the analysis. One patient underwent 2 separate operations, 3 months apart, and required ECLS after each operation. For the analysis, this patient is considered separately on each admission (Patients 6 and 7, Table 1). The patients' demographic data, cardiac defects, surgical repairs, indications for ECLS, types of ECLS, ECLS durations, and long-term outcomes are outlined in Table 1. The mean intraoperative bypass time was 123 minutes \pm 43 (range 69-188 minutes), with a mean crossclamp time of 61 minutes \pm 30 (range 26-116 minutes). Four (40\%) patients had single ventricle physiology. In $3(30 \%)$ patients, ECLS consisted of mechanical ventricular support without an oxygenator; the remaining 7 patients received mechanical ventricular support with an oxygenator. There was no association between the use of an oxygenator and outcome.

\section{Trials of Patients off ECLS}

For the 10 patients studied, there were 18 trials off ECLS. BNP levels were obtained during 16 of these trials. Five (50\%) patients underwent only 1 trial off ECLS. The mean duration of the trials was 94 minutes \pm 102 (range 9-340 minutes). Hemodynamic and biochemical data before (pretrial) and during trials off ECLS (trial) are shown in Table 2. When all trials were taken together, heart rate and central venous pressure increased, and mean arterial pressure decreased from pre-trial values $(P<.05)$. In addition, the inotrope score increased during trials off ECLS $(P<.05)$. Furthermore, serum lactate, the $\mathrm{AVdo}_{2}$, and serum BNP values increased above pre-trial values $(P<.05)$. There was no correlation between the duration of the trials off ECLS and any of the biochemical values or hemodynamic indices.

\section{Separation of Patients From ECLS}

Nine $(90 \%)$ patients were ultimately able to separate from ECLS. One patient who underwent trials off ECLS died 
TABLE 1. Patient demographics

\begin{tabular}{|c|c|c|c|c|c|}
\hline Patient No. & Age & Sex & Weight (kg) & Lesion & Repair \\
\hline 1 & $5 \mathrm{mo}$ & $\mathrm{M}$ & 9 & DORV, uncommitted VSD, RVOT & Intracardiac repair, takedown of repair \\
\hline 2 & $4 \mathrm{~d}$ & $\mathrm{~F}$ & 3 & HLHS & Modified Norwood operation stage I \\
\hline 3 & $3 y$ & M & 14.5 & $\begin{array}{l}\text { Unbalanced AVC, heterotaxy } \\
\text { syndrome, asplenia }\end{array}$ & $\begin{array}{l}\text { Fontan operation, AV valve repair, } \\
\text { focalization of hepatic veins }\end{array}$ \\
\hline 4 & $1 d$ & $\mathrm{M}$ & 2.6 & TGA & Arterial switch \\
\hline 5 & $5 d$ & $\mathrm{M}$ & 2.34 & $\begin{array}{l}\text { VSD, ASD, hypoplastic aortic } \\
\text { isthmus/transverse arch }\end{array}$ & VSD closure, aortic arch reconstruction \\
\hline $6^{*}$ & $3 \mathrm{mo}$ & $\mathrm{F}$ & 3.2 & $\begin{array}{l}\text { VSD, ASD, AS, hypoplasia of } \\
\text { ascending aorta, aortic arch } \\
\text { obstruction }\end{array}$ & VSD closure, aortic arch reconstruction \\
\hline $7^{*}$ & $5 \mathrm{mo}$ & $\mathrm{F}$ & 4 & AS, Al, aortic arch obstruction & Ross-Konno, ascending aorta augumentation \\
\hline 8 & $3 \mathrm{mo}$ & $\mathrm{F}$ & 3.72 & $\begin{array}{l}\text { DORV, hypoplastic RV, } \\
\text { Taussig-Bing anomaly }\end{array}$ & Modified Norwood operation \\
\hline 9 & $2 \mathrm{mo}$ & $\mathrm{F}$ & 4.8 & ALCAPA & Translocation of left coronary to aorta \\
\hline 10 & $2 d$ & M & 3.2 & TAPVR, restrictive ASD & Complete repair \\
\hline
\end{tabular}

ECLS, Extracorporeal life support; DORV, double-outlet right ventricle; VSD, ventricular septal defect; RVOT, right ventricular outflow tract obstruction; $H L H S$, hypoplastic left heart syndrome; $A V C$, atrioventricular canal; $A V$, atrioventricular; $T G A$, transposition of great arteries; $C P B$, cardiopulmonary bypass; $A S D$, atrial septal defect; $A S$, aortic valve stenosis; $A l$, aortic insufficiency; $R V$, right ventricle; $O R$, operating room; $A L C A P A$, anomalous left coronary artery from the pulmonary artery; TAPVR, total anomalous pulmonary venous return. ${ }^{*}$ The same patient with two different admissions 3 months apart.

without separating from ECLS. In both the poor and good short-term outcome groups, mean arterial pressure decreased, and central venous pressure, heart rate, and inotropic score increased during the trials $(P<.05)$.

Biochemical changes during the trials for each group are shown in Figure 1. Serum BNP and lactate levels tended to increase in the poor short-term outcome group, but these changes did not reach significance (Figure 1). However, the $\mathrm{AVdO}_{2}$ was significantly higher in the poor short-term outcome group than in the good short-term outcome group (Figure $1 ; P<.05$ ). In fact, an $\mathrm{AVdo}_{2}$ of greater than 40 during a trial off ECLS had a sensitivity of $100 \%$ and a specificity of $70 \%$ for predicting a poor short-term outcome $(P<.05)$.

\section{Long-term Outcomes}

The long-term outcome for each patient can be seen in Table 1 . There were $5(50 \%)$ poor long-term outcomes and $5(50 \%)$ good long-term outcomes. One patient (patient 1, Table 1) required an unplanned operation within 3 months after ECLS and died within 6 months of ECLS. The unplanned operation is considered the single poor outcome for this patient. Thus, $3(30 \%)$ patients died within 3 months after ECLS, and $2(20 \%)$ patients required an unplanned operation within 3 months after ECLS.

Patients with poor long-term outcomes had a longer aortic crossclamp time (43 minutes \pm 14 vs 78 minutes \pm
29; $P<.05)$ and more trials off ECLS $(1.4 \pm 0.5$ vs $2.8 \pm$ $1.1 ; P<.05)$ than patients with good long-term outcomes. There were no significant differences between the two groups in age, weight, type of cardiac defect, preoperative BNP levels, bypass time, ECLS duration, or hospital days. In addition, there were no significant differences between the groups in pre-trial or trial mean arterial pressures, central venous pressures, heart rates, urine output, or inotrope scores.

Days in the PCICU tended to be longer in the poor outcome group, but the difference did not reach significance ( 25 days \pm 13.6 vs 13.4 days $\pm 6.6 ; P=.12$ ). Patients in the poor outcome group had fewer mechanical ventilationfree days than patients in the good outcome group (8.4 days \pm 8.1 vs 20 days $\pm 5.7 ; P<.05$ ).

Biochemical changes during the final trial off ECLS for patients with good and poor long-term outcomes are shown in Figure 2. There were no differences in the $\mathrm{AVdo}_{2}$ or in the change in lactate during the trials between groups (Figure 2). Pre-trial lactate levels were greater in the poor long-term outcome group than in the good long-term outcome group $(1.8 \mathrm{mmol} / \mathrm{L} \pm 1.0 \mathrm{vs} 1.0$ $\mathrm{mmol} / \mathrm{L} \pm 0.21 ; P=.11)$, but the values were within the normal range and were not predictive of outcome. Absolute lactate levels during the trials were also not predictive of outcome. 
TABLE 1. Continued.

\begin{tabular}{|c|c|c|c|}
\hline Indication for ECLS & Use of oxygenator & ECLS duration (d) & Long-term outcome \\
\hline Postoperative cardiac arrest & Yes & 2 & $\begin{array}{l}\text { Unplanned operation within } 3 \text { mo, } \\
\text { death within } 6 \text { mo }\end{array}$ \\
\hline Low cardiac output syndrome & Yes & 7 & $\begin{array}{l}\text { Death with multiorgan failure } 48 \mathrm{~h} \text { after } \\
\text { separation from ECLS }\end{array}$ \\
\hline Low cardiac output syndrome & Yes & 4 & $\begin{array}{l}\text { No need for further intervention after } \\
\text { separation from ECLS }\end{array}$ \\
\hline Inability to separate from CPB & No & 3 & $\begin{array}{l}\text { No need for further intervention after } \\
\text { separation from ECLS }\end{array}$ \\
\hline Low cardiac output syndrome & Yes & 10 & Death, inability to wean from ECLS \\
\hline Postoperative cardiac arrest & No & 4 & Unplanned operation within 3 mo \\
\hline Inability to separate from CPB & Yes & 8 & Death within 3 mo \\
\hline $\begin{array}{l}\text { Low cardiac output after CPB } \\
\text { (elective initiation in } \mathrm{OR} \text { ) }\end{array}$ & No & 4 & $\begin{array}{l}\text { No need for further intervention after } \\
\text { separation from ECLS }\end{array}$ \\
\hline Inability to separate from CPB & No & 2 & $\begin{array}{l}\text { No need for further intervention after } \\
\text { separation from ECLS }\end{array}$ \\
\hline Inability to separate from CPB & Yes & 3 & $\begin{array}{l}\text { No need for further intervention after } \\
\text { separation from ECLS }\end{array}$ \\
\hline
\end{tabular}

The change in BNP during a trial, as defined by the ratio of the trial to pre-trial BNP level, was significantly higher in the poor long-term outcome group than in the good longterm outcome group (Figure $2 ; P<.05$ ). BNP levels decreased from pre-trial levels during the final trials off ECLS in all 5 patients with a good long-term outcome (from 388 $\mathrm{pg} / \mathrm{mL} \pm 309$ to $306 \mathrm{pg} / \mathrm{mL} \pm 246 ; P=.05)$ and increased during the final trials in 4 of the 5 patients with a poor long-term outcome (from $638 \mathrm{pg} / \mathrm{mL} \pm 310$ to $953 \mathrm{pg} / \mathrm{mL} \pm$ $575 ; P=.07$ ). The 1 patient (patient 2, Table 1 ) with a poor long-term outcome who had a decrease in BNP during the final trial off ECLS was separated from ECLS but 48 hours later had support withdrawn owing to multisystem organ failure. In fact, an increase in BNP during the final trial off

TABLE 2. Hemodynamic and biochemical data in all patients before (pre-trial) and during (trial) trials0020off ECLS

\begin{tabular}{lccc}
\hline & Pre-trial & Trial & $P$ value \\
\hline Lactate (mmol/L) & $1.44 \pm 0.71$ & $2.6 \pm 1.9$ & .005 \\
Inotropic score & $15.6 \pm 5.2$ & $21.1 \pm 9.1$ & .002 \\
HR (beats/min) & $136 \pm 17$ & $152 \pm 21$ & .008 \\
$\mathrm{MAP}(\mathrm{mm} \mathrm{Hg})$ & $62 \pm 11$ & $50 \pm 10$ & .002 \\
$\mathrm{CVP}(\mathrm{mm} \mathrm{Hg})$ & $10 \pm 4$ & $15 \pm 4$ & $<.0001$ \\
$\mathrm{ScVO}_{2}(\%)$ & $72 \pm 14$ & $50 \pm 22$ & .0005 \\
$\mathrm{AVdO}_{2}(\%)$ & $28.5 \pm 14.2$ & $44.2 \pm 20.2$ & .004 \\
$\mathrm{BNP}(\mathrm{pg} / \mathrm{mL})$ & $581 \pm 382$ & $777 \pm 637$ & .03 \\
\hline
\end{tabular}

$H R$, Heart rate; $M A P$, mean arterial pressure; $C V P$, central venous pressure; $\mathrm{SCVO}_{2}$, central venous oxygen saturation; $\mathrm{AVdO}_{2}$, arterial-venous oxyhemoglobin saturation difference; $B N P$, B-type natriuretic peptide.
ECLS (trial/pre-trial ratio of $>1$ ) had a sensitivity of $80 \%$ and a specificity of $100 \%$ for predicting a poor long-term outcome $(P<.05)$.

\section{Discussion}

These data indicate that BNP may have clinical utility as a biomarker for infants and children requiring ECLS after cardiac surgery. Although BNP levels during trials off ECLS did not predict subsequent separation from ECLS, an increase in BNP during the final trial off ECLS was associated with the need for an unplanned operation or death within 3 months. Interestingly, no other changes during trials off ECLS were associated with these long-term outcomes, and thus BNP may reflect myocardial derangements in a manner not captured by other physiologic markers.

We chose to investigate BNP because it is a cardiac hormone integrally related to the myocardium, as opposed to other biomarkers that reflect more global processes. BNP is a member of a structurally related group of peptide hormones, termed natriuretic peptides. Biosynthesis of BNP begins with a 134-amino acid precursor, which is cleaved in steps to form the active C-terminal 32-amino acid hormone, BNP, and the inactive $N$-terminal proBNP. Active BNP is stored in the atria in specific storage organelles. ${ }^{23}$ Basal BNP levels result from continuous secretion from the atria. With acute myocardial distention, BNP release increases greatly from this depletable storage pool, in a manner independent of BNP synthesis. However, under chronic conditions of increased cardiac volume loading, such as congestive heart failure, increases in circulating BNP are 


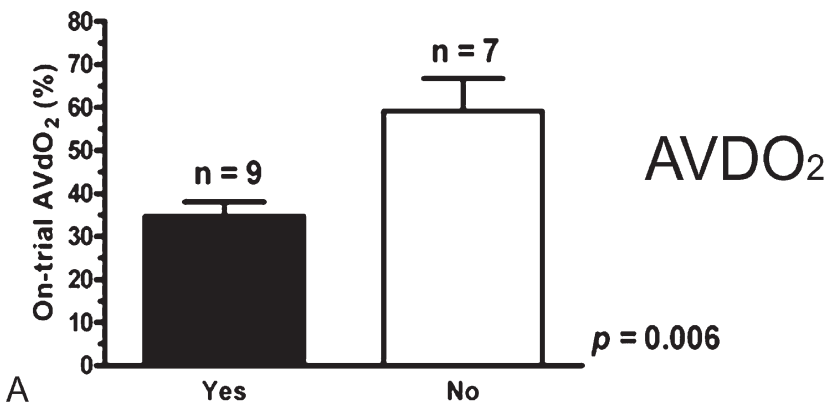

A
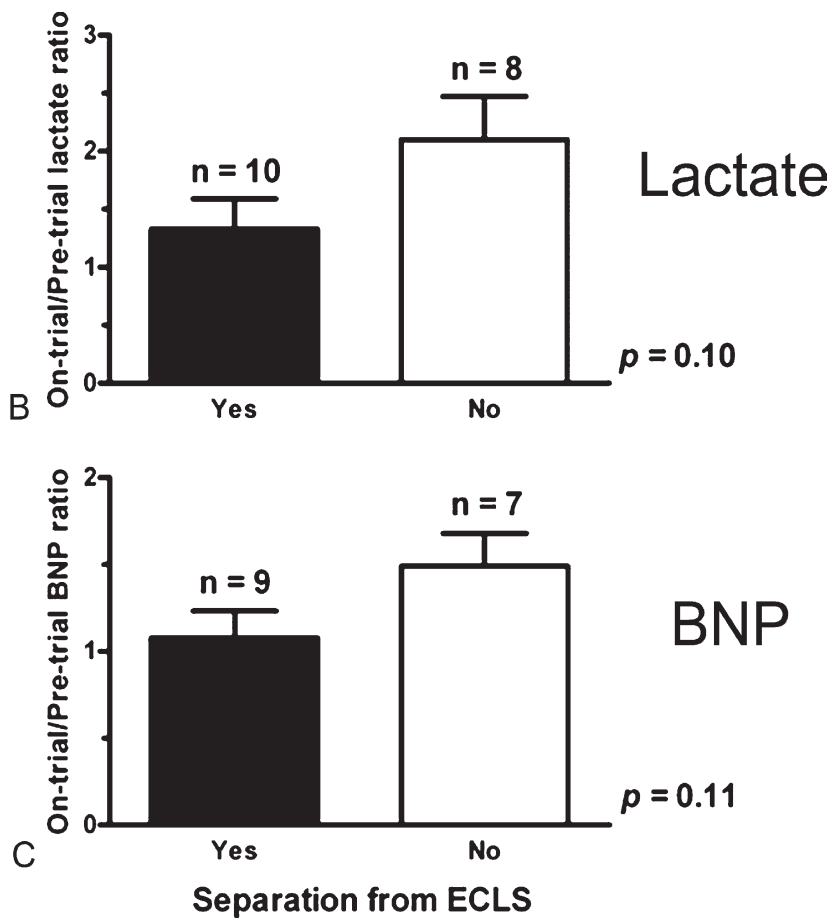

Figure 1. Biochemical changes during trials off extracorporeal life support (ECLS) in patients with good and poor short-term outcomes. A good short-term outcome was defined as the separation from ECLS after a trial, and a poor short-term outcome was defined as the resumption of ECLS after a trial. A, The arterialvenous oxyhemoglobin saturation difference $\left(\mathrm{AVdO}_{2}\right)$ was significantly greater in the poor short-term outcome group than the good short-term outcome group. $B$, The change in lactate during trials is expressed as the ratio of the level during the trial (on-trial) to the level before the trial (pre-trial). The change in lactate during trials was not significantly different between groups. C, The change in B-type natriuretic peptide (BNP) during trials is expressed as the ratio of the level during the trial to the level before the trial. The change in BNP during trials was not significantly different between groups.

maintained owing to ventricular re-expression of the fetal gene program..$^{24-26}$ In addition, acute myocardial ischemia and inflammatory mediators, such as tumor necrosis factor- $\alpha$ and interleukin- $1 \beta$, result in rapid ventricular ex-
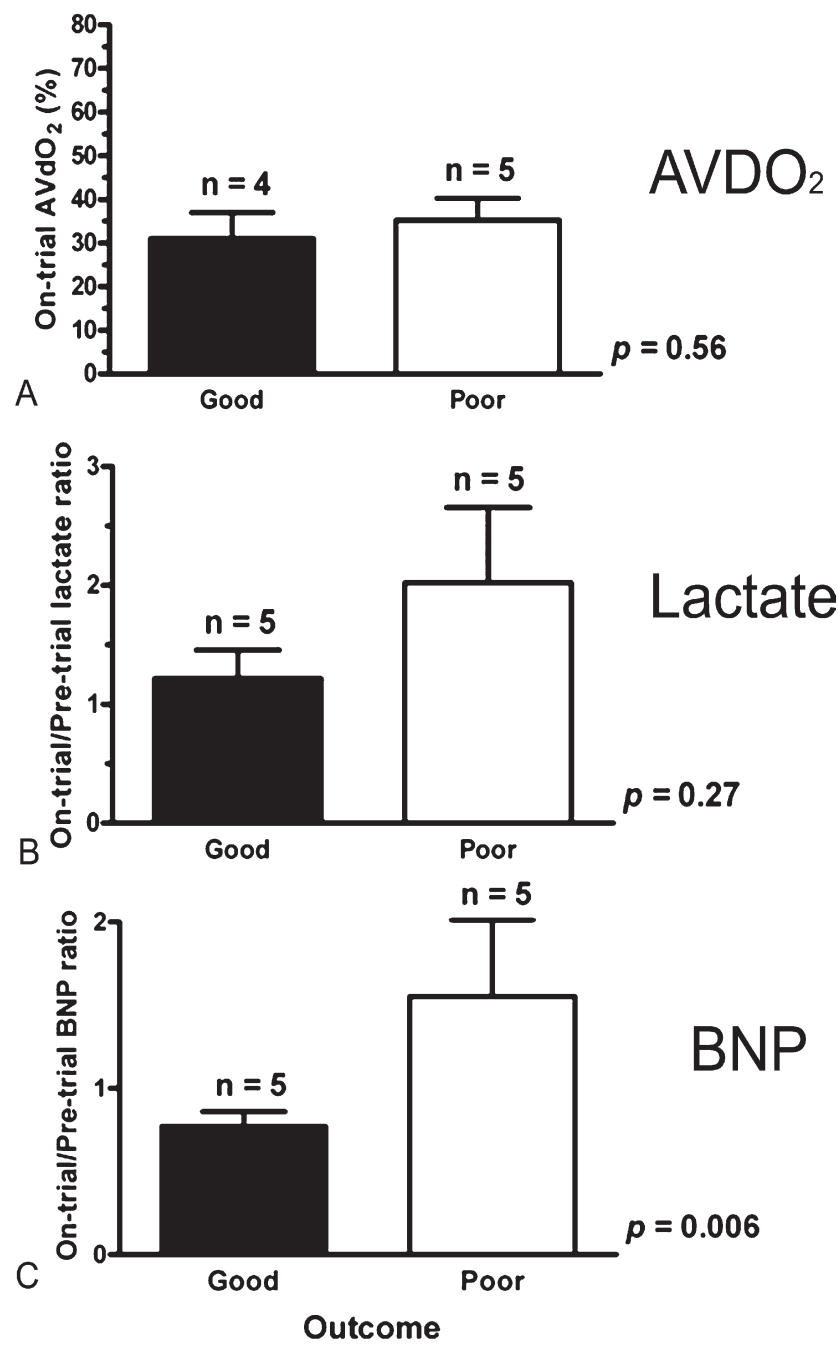

Figure 2. Biochemical changes during the final trials off extracorporeal life support (ECLS) in patients with good and poor long-term outcomes. Good and poor long-term outcomes were defined as the absence and presence, respectively, of an unplanned cardiac operation or death with 3 months after the operation. A, The arterial-venous oxyhemoglobin saturation difference $\left(\mathrm{AVdO}_{2}\right)$ was not different between groups. $\mathrm{B}$, The change in lactate during trials is expressed as the ratio of the level during the trial (on-trial) to the level before the trial (pre-trial). The change in lactate during the final trials off ECLS was not significantly different between groups. C, The change in BNP during trials is expressed as the ratio of the level during the trial to the level before the trial. BNP levels during the final trials off ECLS increased to a greater extent in patients with a poor long-term outcome than patients with a good long-term outcome.

pression of BNP. ${ }^{26,27}$ The primary actions of BNP, which are mediated by the secondary messenger cGMP, are vascular smooth muscle relaxation, diuresis, and natriuresis. Clearance of BNP, which has a half-life of approximately 
20 minutes, occurs through degradation by an endopeptidase, and by endocytosis through a specific natriuretic peptide receptor, termed NPR-C. Owing to these characteristics, BNP has been successfully used as a biomarker in adult and, to a lesser extent, pediatric cardiac disease. ${ }^{11-15}$

In fact, alterations in BNP during mechanical myocardial support, including support for pediatric patients after cardiac surgery, have been investigated previously. ${ }^{18-20,28}$ In adult patients with cardiac failure, the use of ventricular assist devices has been shown to decrease BNP levels and gene expression. ${ }^{18,19,28}$ In a recent study, Huang and colleagues ${ }^{20}$ studied 15 pediatric patients requiring ECLS for cardiogenic shock. Shock developed after cardiac surgery in 11 of the 15 patients. These investigators did not find an association between BNP levels during the course of ECLS and survival after ECLS. However, they did find that BNP levels on the first and fourth days after separation from ECLS were significantly higher in nonsurvivors than survivors. ${ }^{20}$ In contrast to the present study, these investigators determined BNP levels on ECLS before weaning, when the heart was fully supported. This support may have confounded any association between BNP and the underlying condition of the myocardium.

Cardiovascular hemodynamics may be significantly altered during mechanical support of the heart, particularly ventricular loading conditions. Thus, we believed that BNP determinations off ECLS would have the greatest potential clinical utility. However, several factors obviate the use of absolute BNP values in pediatric patients after cardiac surgery. Perhaps most important, the available data on BNP in patients with congenital cardiac defects suggest that BNP levels vary substantially depending on the specific defect. ${ }^{29-32}$ Furthermore, BNP levels are altered after operations with $\mathrm{CPB}$ in a manner that also appears in part dependent on the underlying defect, and BNP levels vary with age with levels highest at birth, followed by a fall in the first 2 weeks after birth to levels generally below that of adults. ${ }^{32-34}$ Therefore, we chose to assess the degree of change in BNP during a trial to control for variability in baseline BNP levels between patients. Although we expected BNP levels to increase in all trials off ECLS, owing to increased cardiac volume loading, we hypothesized that the magnitude of the change would differ significantly between patients with persistent myocardial dysfunction and patients with adequate recovery. In fact, when all trials off ECLS were analyzed together, mean BNP levels did increase (from $581 \mathrm{pg} / \mathrm{mL} \pm 382$ to $777 \mathrm{pg} / \mathrm{mL} \pm 637 ; P<$ $.05)$; however, quite surprisingly, in all patients with a good long-term outcome, BNP levels actually decreased during trials off ECLS. The mechanism for this decrease is unclear and warrants further study.

Clinically, the recovery of adequate cardiovascular function is the key requirement to separate patients from ECLS.
Therefore, accurate clinical assessments of cardiovascular function during weaning from ECLS are critical. Our data exemplify the difficulties inherent in these assessments. During trials off ECLS, we found significant increases in lactate, inotrope score, central venous pressure, heart rate, $\mathrm{BNP}$, and the $\mathrm{AVdO}_{2}$. In addition, we found significant decreases in mean arterial pressure and central venous oxygen saturations. Importantly, we did not find an association between the duration of the trials with any of the biochemical or hemodynamic indices. However, only the $\mathrm{AVdO}_{2}$ correlated with the ability to separate from ECLS after a trial. We did not use a defined protocol to guide decisions about separating patients from ECLS, and thus it is in fact more accurate to state that the $\mathrm{AVdo}_{2}$ was correlated with the decision to separate patients from ECLS, whereas the other factors were not. That is, patients not separated from ECLS after a trial may have survived separation. Furthermore, because the cardiac team was not blinded to any of the hemodynamic or biochemical data, other than BNP, in reaching a decision to separate from ECLS we likely considered some or all of these factors. Nevertheless, assessments of the $\mathrm{AVdo}_{2}$ are known to improve the management of pediatric patients after cardiac surgery, and thus our data suggest that this may also apply to the subset of these patients that requires ECLS postoperatively. ${ }^{35}$

Despite an increase in the use of ECLS for pediatric patients after cardiac surgery, mortality has remained at approximately $60 \%$ to $70 \% .^{5,9,36}$ In our study, $3(30 \%)$ patients died within 3 months of ECLS and an additional patient died within 6 months. Previous factors that have been reported to predict death in pediatric patients on ECLS include age, gender, lactate, type of cardiac defect, inotrope score, renal failure, hepatic failure, multisystem organ failure, duration of ECLS, sepsis, arrhythmia before ECLS, and the duration of mechanical ventilation before ECLS. ${ }^{1,3,5,36,37}$ None of these associations was identified in the current study, which may relate to its small sample size. However, in our study only the change in BNP during the final trial off ECLS, predicted poor long-term outcomes.

Two patients required an unplanned operation within 3 months of ECLS. One patient (patient 1, Table 1) required pulmonary artery banding for excessive pulmonary blood flow owing to left-to-right shunting, and the second patient (patient 6, Table 1) required a Ross-Konno procedure and aortic arch augmentation for aortic stenosis, aortic obstruction, and aortic insufficiency. All patients had transesophageal echocardiography performed at least once while receiving ECLS. In addition, echocardiography was performed during 6 of the 9 final trials off ECLS. The present study design does not allow comparisons between risk stratification based on echocardiography and BNP levels. However, after echocardiography was performed, patients who ulti- 
mately died or required an unplanned operation were separated from ECLS. Although echocardiography can precisely identify the cardiac anatomy and function at the time of the study, assessing the long-term impact of a finding (eg, left-to-right shunting) requires subjective judgments. Our data suggest that BNP may provide additional information that might strengthen these judgments.

The management of pediatric patients requiring ECLS after cardiac surgery is daunting. Unfortunately, few studies have put forth potential tools to aid in the management of these patients. This pilot study, although preliminary owing to its sample size and heterogeneous population, suggests that BNP determinations during trials off ECLS allow for risk stratification. The availability of this information before removal of the ECLS cannulas could allow for important decisions to be made at a time when full mechanical support can be readily re-established or increased. If BNP levels increase during a trial off ECLS, physicians might consider re-evaluation of potential surgical options or consider whether the patient would be a transplant candidate. Further studies are warranted to confirm and define a role for BNP in this vulnerable patient population.

We thank Megan Tracey, PNP, Julie Bushnell, PNP, Laura Presnell, ACNP, the Pediatric Critical Care Fellows, the Cardiac Intensive Care Nurses, the Pediatric Clinical Research Center, Adam Gorham, and Leslie Kurkjian for their invaluable assistance with the study.

\section{References}

1. Baslaim G, Bashore J, Al-Malki F, Jamjoom A. Can the outcome of pediatric extracorporeal membrane oxygenation after cardiac surgery be predicted? Ann Thorac Cardiovasc Surg. 2006;12:21-7.

2. Raithel SC, Pennington DG, Boegner E, Fiore A, Weber TR. Extracorporeal membrane oxygenation in children after cardiac surgery. Circulation. 1992;86(5 Suppl):II305-10.

3. Huang SC, Wu ET, Chen YS, Chang CI, Chiu IS, Chi NH, et al. Experience with extracorporeal life support in pediatric patients after cardiac surgery. ASAIO J. 2005;51:517-21.

4. Ghez O, Feier H, Ughetto F, Fraisse A, Kreitmann B, Metras D. Postoperative extracorporeal life support in pediatric cardiac surgery: recent results. ASAIO J. 2005;51:513-6.

5. Morris MC, Ittenbach RF, Godinez RI, Portnoy JD, Tabbutt S, Hanna $\mathrm{BD}$, et al. Risk factors for mortality in 137 pediatric cardiac intensive care unit patients managed with extracorporeal membrane oxygenation. Crit Care Med. 2004;32:1061-9.

6. Groom RC. Pediatric cardiopulmonary bypass devices: trends in device use for cardiopulmonary bypass and postcardiotomy support. ASAIO J. 2005;51:525-9.

7. Shen I, Ungerleider RM. Routine use of mechanical ventricular assist following the Norwood procedure. Semin Thorac Cardiovasc Surg Pediatr Card Surg Annu. 2004;7:16-21.

8. Ungerleider RM, Shen I, Yeh T, Schultz J, Butler R, Silberbach M, et al. Routine mechanical ventricular assist following the Norwood procedure-improved neurologic outcome and excellent hospital survival. Ann Thorac Surg. 2004;77:18-22.

9. Conrad SA, Rycus PT, Dalton H. Extracorporeal Life Support Registry Report 2004. ASAIO J. 2005;51:4-10.

10. Yandle TG. Biochemistry of natriuretic peptides. J Intern Med. 1994; 235:561-76.
11. Doust JA, Glasziou PP, Pietrzak E, Dobson AJ. A systematic review of the diagnostic accuracy of natriuretic peptides for heart failure. Arch Intern Med. 2004;164:1978-84.

12. Doust JA, Pietrzak E, Dobson A, Glasziou P. How well does B-type natriuretic peptide predict death and cardiac events in patients with heart failure: systematic review. BMJ. 2005;330:625.

13. Troughton RW, Frampton CM, Yandle TG, Espiner EA, Nicholls MG, Richards AM. Treatment of heart failure guided by plasma aminoterminal brain natriuretic peptide (N-BNP) concentrations. Lancet. 2000; 355:1126-30.

14. Costello JM, Goodman DM, Green TP. A review of the natriuretic hormone system's diagnostic and therapeutic potential in critically ill children. Pediatr Crit Care Med. 2006;7:308-18.

15. Price JF, Thomas AK, Grenier M, Eidem BW, O'Brian Smith E, Denfield SW, et al. B-type natriuretic peptide predicts adverse cardiovascular events in pediatric outpatients with chronic left ventricular systolic dysfunction. Circulation. 2006;114:1063-9.

16. Salzberg S, Lachat M, Zund G, Oechslin E, Schmid ER, DeBakey M, et al. Left ventricular assist device as bridge to heart transplantationlessons learned with the MicroMed DeBakey axial blood flow pump. Eur J Cardiothorac Surg. 2003;24:113-8.

17. Ohata T, Sakakibara T, Takano H, Izutani H. Plasma brain natriuretic peptide reflects left ventricular function during percutaneous cardiopulmonary support. Ann Thorac Surg. 2004;77:164-7.

18. Sodian R, Loebe M, Schmitt C, Potapov EV, Siniawski H, Muller J, et al. Decreased plasma concentration of brain natriuretic peptide as a potential indicator of cardiac recovery in patients supported by mechanical circulatory assist systems. J Am Coll Cardiol. 2001;38:1942-9.

19. Thompson LO, Skrabal CA, Loebe M, Lafuente JA, Roberts RR, Akgul A, et al. Plasma neurohormone levels correlate with left ventricular functional and morphological improvement in LVAD patients. J Surg Res. 2005;123:25-32.

20. Huang SC, Wu ET, Ko WJ, Lai LP, Hsu J, Chang CI, et al. Clinical implication of blood levels of B-type natriuretic peptide in pediatric patients on mechanical circulatory support. Ann Thorac Surg. 2006; 81:2267-72.

21. Karl TR, Horton SB. Ventricular assist device support in pediatric patients. In: Chang A, editor. Heart failure in children and young adults. Philadelphia: Saunders-Elsevier; 2006. p. 664-79.

22. Wernovsky G, Wypij D, Jonas RA, Mayer JE Jr, Hanley FL, Hickey $\mathrm{PR}$, et al. Postoperative course and hemodynamic profile after the arterial switch operation in neonates and infants. A comparison of low-flow cardiopulmonary bypass and circulatory arrest. Circulation. 1995;92:2226-35.

23. McGrath MF, de Bold ML, de Bold AJ. The endocrine function of the heart. Trends Endocrinol Metab. 2005;16:469-77.

24. Zhang Y, Carreras D, de Bold AJ. Discoordinate re-expression of cardiac fetal genes in N(omega)-nitro-L-arginine methyl ester (LNAME) hypertension. Cardiovasc Res. 2003;57:158-67.

25. Schaub MC, Hefti MA, Harder BA, Eppenberger HM. Various hypertrophic stimuli induce distinct phenotypes in cardiomyocytes. $J \mathrm{Mol}$ Med. 1997;75:901-20.

26. Hama N, Itoh H, Shirakami G, Nakagawa O, Suga S, Ogawa Y, et al Rapid ventricular induction of brain natriuretic peptide gene expression in experimental acute myocardial infarction. Circulation. 1995; 92:1558-64.

27. Ma KK, Ogawa T, de Bold AJ. Selective upregulation of cardiac brain natriuretic peptide at the transcriptional and translational levels by pro-inflammatory cytokines and by conditioned medium derived from mixed lymphocyte reactions via p38 MAP kinase. J Mol Cell Cardiol. 2004;36:505-13.

28. Kuhn M, Voss M, Mitko D, Stypmann J, Schmid C, Kawaguchi N, et al. Left ventricular assist device support reverses altered cardiac expression and function of natriuretic peptides and receptors in end-stage heart failure. Cardiovasc Res. 2004;64:308-14.

29. Cowley CG, Bradley JD, Shaddy RE. B-type natriuretic peptide levels in congenital heart disease. Pediatr Cardiol. 2004;25:336-40.

30. Law YM, Ettedgui J, Beerman L, Maisel A, Tofovic S. Comparison of plasma B-type natriuretic peptide levels in single ventricle patients with systemic ventricle heart failure versus isolated cavopulmonary failure. Am J Cardiol. 2006;98:520-4. 
31. Koch A, Zink S, Singer H. B-type natriuretic peptide in paediatric patients with congenital heart disease. Eur Heart J. 2006;27:861-6.

32. Sun LS, Dominguez C, Mallavaram NA, Quaegebeur JM. Dysfunction of atrial and B-type natriuretic peptides in congenital univentricular defects. J Thorac Cardiovasc Surg. 2005;129:1104-10.

33. Koch A, Singer H. Normal values of B type natriuretic peptide in infants, children, and adolescents. Heart. 2003;89:875-8.

34. Shih CY, Sapru A, Oishi P, Azakie A, Karl TR, Harmon C, et al. Alterations in plasma B-type natriuretic peptide levels after repair of congenital heart defects: a potential perioperative marker. $J$ Thorac Cardiovasc Surg. 2006;131:632-8.
35. Tweddell JS, Hoffman GM. Postoperative management in patients with complex congenital heart disease. Semin Thorac Cardiovasc Surg Pediatr Card Surg Annu. 2002;5:187-205.

36. Hoskote A, Bohn D, Gruenwald C, Edgell D, Cai S, Adatia I, et al. Extracorporeal life support after staged palliation of a functional single ventricle: subsequent morbidity and survival. J Thorac Cardiovasc Surg. 2006;131:1114-21.

37. Cheung PY, Etches PC, Weardon M, Reynolds A, Finer NN, Robertson CM. Use of plasma lactate to predict early mortality and adverse outcome after neonatal extracorporeal membrane oxygenation: a prospective cohort in early childhood. Crit Care Med. 2002;30:2135-9. 